\title{
An Investigation of Aerosol Size Distribution Properties at Dibrugarh: North-Eastern India
}

\author{
Mukunda Madhab Gogoi ${ }^{1}$, Pradip Kumar Bhuyan ${ }^{2, *}$, and Krishnaswamy Krishna Moorthy ${ }^{1}$ \\ ${ }^{1}$ Space Physics Laboratory, Vikram Sarabhai Space Center, Thiruvananthapuram 695 022, India \\ ${ }^{2}$ Department of Physics, Dibrugarh University, Dibrugarh 786 004, India
}

Received 16 November 2007, accepted 11 June 2008

\begin{abstract}
Columnar aerosol size distributions, retrieved from spectral AOD (aerosol optical depth) estimates over a northeastern location of India (Dibrugarh) are, in general, bimodal with the occurrence of primary (broad) mode at $0.04-0.17 \mu \mathrm{m}$ and the secondary mode at $0.88-1.29 \mu \mathrm{m}$. The physical parameters of size distributions representing the microphysical properties of aerosols show distinct seasonal variations with the highest value of the effective radii $(\sim 0.55 \mu \mathrm{m})$ during pre-monsoon (March to May) season which, along with the highest value of AOD $(\sim 0.46 \pm 0.09)$ during the same season, is attributed to the maximum abundance of coarse particles. Examining the results in the light of the HYSPLIT back trajectory analysis and the peculiar topography of northeast India allowing advection only from the Indo-Gangetic plains or Bay-of-Bengal, it appears that the strong presence of the coarse mode aerosols are associated with either mineral dust or marine aerosol components or both.
\end{abstract}

Key words: Aerosol optical depth, Columnar size distribution, Multiwavelength solar radiometer, HYSPLIT

Citation: Gogoi, M. M., P. K. Bhuyan, and K. K. Moorthy, 2009: An investigation of aerosol size distribution properties at Dibrugarh: North-eastern India. Terr. Atmos. Ocean. Sci., 20, 521-533, doi: 10.3319/TAO.2008.06.11.01(A)

\section{INTRODUCTION}

Information on the distribution of atmospheric aerosol is important for the understanding of physical processes relating to studies of weather, climate, atmospheric electricity, air pollution, and aerosol physics. Because of their capacity to directly alter the rate of transfer of solar radiation and indirectly affect the complex phenomena connected with cloud and precipitation processes, aerosols are of considerable interest to atmospheric scientists. Produced by a variety of natural and anthropogenic sources, aerosols frequently exhibit widely varying optical properties over time due to diffusion and aging processes such as coagulation, humidification, scavenging by precipitation and gas to particle conversion. Combined with varying source strengths and due to advection by local to synoptic meteorological processes, aerosols form a dynamic atmospheric constituent for effects on climate, environment and public health (Smirnov et al. 2002). The climate effects are crucially dependent on aerosol properties, such as size distribution, chemical composition, and degree of internal and external mixing. Estimates

\footnotetext{
* Corresponding author

E-mail:pkbhuyan@gmail.com
}

of climate impact are further complicated by high spatial and temporal variability in aerosol properties (Pilinis et al. 1995; Anderson et al. 2003). Measurement of aerosol optical depths (AOD) and columnar size distributions (CSD) are thus important for the study of earth's radiation budget, remote sensing, and climate research. The size distribution function describes how the various physical parameters of aerosols are distributed as a function of their sizes.

The size distribution of aerosols at any given location is mainly determined by the relative strength of different production and removal processes (Jaenicke 1993; Raes 1995; Schwartz et al. 1995). In spite of increased research activities during recent years, the origin of sub-micrometer particles in the atmosphere is one of the major open questions in ambient aerosol research. However, when urban air is considered, the origin of particles is more complicated. It is well known that traffic and other anthropogenic combustion sources are the most important sources of all air pollution compounds in urban air including fine particles (Derwent et al. 1995). Also the nucleation mode particles (particle diameter less than $20 \mathrm{~nm}$ ) have been found to originate from traffic (Vävekä et al. 2000). Since the sources of anthro- 
pogenic aerosols are located primarily on land, the concentration of anthropogenic aerosols tends to be much larger over land than the open ocean. The land response to surface radiation flux changes much more quickly than the ocean because of its lower heat capacity and hence the presence of aerosols (especially absorption types such as soot) over land have more significant climate effects than those over the ocean (Hansen et al. 1998).

In this paper, we report the characteristics of aerosol size distribution retrieved from spectral AOD estimates over Dibrugarh and investigate the effect of meteorological factors, especially rain and wind, as well as synoptic-scale phenomena on aerosol particle number concentrations and size distributions.

\section{STATION AND INSTRUMENTATION}

Dibrugarh $\left(27.3^{\circ} \mathrm{N}, 94.6^{\circ} \mathrm{E}, 111 \mathrm{~m}\right.$ amsl $)$ is located close to the northeastern boundary of India, in the northeastern corner of the upper Brahmaputra valley (Fig. 1). The unique peculiarity of the valley is such that it is surrounded by the great Himalayan range and Tibetan Plateau to the north, Garo-Khasi-Jayantia and Naga hills to the south and mountains of Yanan to the east, but is open to the west side towards the Indo-Gangetic plains. The area is endowed with extensive water resources. No significant local pollution sources are present in the proximity of the site, except for ve-

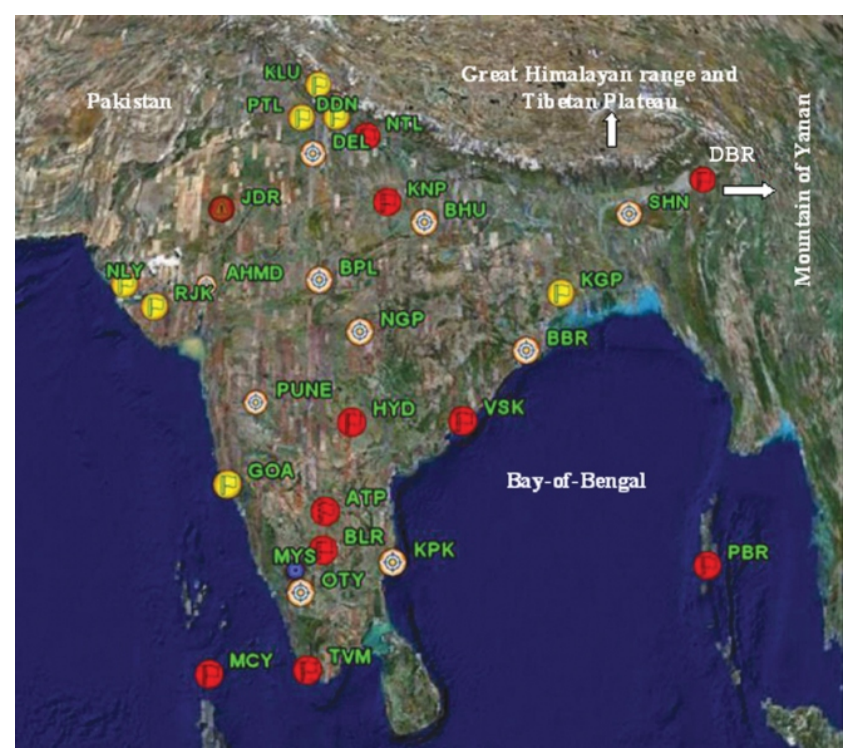

Fig. 1. MWR station at Dibrugarh (DBR) in northeastern India along with the other ground based MWR observatories [Kullu (KLU), Patiala (PTL), Dehradun (DDN), Nainital (NTL), Delhi (DEL), Jodhpur (JDR), Kanpur (KNP), Banaras (BHU), Shillong (SHN), Naliya (NLY), Rajkot (RJK), Ahmedabad (AHMD), Bhopal (BPL), Kharagpur (KGP), Nagpur (NGP), Bhubaneswar (BBR), Pune (PUNE), Hyderabad (HYD), Visakhapatnam (VSK), Goa (GOA), Anantapur (ATP), Bangalore (BLR), Kalppakkam (KPK), Mysore (MYS), Port-Blair (PBR), Ooty (OTY), Minicoy (MCY) and Trivandrum (TVM)] across the country. hicle exhaust from the National Highway running close to the selected site.

On the basis of the climatic characteristics of different meteorological parameters such as distribution of temperature, rainfall, rainy days, humidity, presence of fogs, and thunderstorms, the climate of the area is classified into four seasons. The dry and cold winter (December to February) is associated with fog and hazes, while the upper pressure level westerly air masses significantly influence the aerosol properties at Dibrugarh during pre-monsoon (March to May) season. The monsoon (June to September) season is characterized by heavy rains, which decrease abruptly in the retreating-monsoon (October and November) season.

Study of the characterization of atmospheric aerosols at Dibrugarh in the entire northeastern part of the country has been carried out since October 2001 by using a ground based Multi-Wavelength solar Radiometer (MWR). The country is covered by a broadly distributed network of MWRs that form part of the Indian Space Research Organization's Geosphere Biosphere Program (ISRO-GBP). This network measures spectral extinction of solar flux as a function of solar zenith angle at ten narrow wavelength bands centered at $0.38,0.40,0.45,0.50,0.60,0.65,0.75,0.85,0.935$, and $1.025 \mu \mathrm{m}$ with full width at half maximum bandwidth of 5 to $6 \mathrm{~nm}$. The MWR, designed on the principle of filter wheel radiometers (Shaw et al. 1973; Tomasi et al. 1983) was operated from the rooftop of the building of the Physics Department of Dibrugarh University ( $\sim 8 \mathrm{~m}$ above ground) on all days when unobstructed solar visibility was available for at least 2 to $3 \mathrm{hrs}$. Spectral AODs (denoted by $\tau_{\mathrm{p} \lambda}$ ) are estimated by analyzing the MWR data following the Langley technique (Shaw et al. 1973; Tomasi et al. 1983). In analyzing the MWR data, the data collected during the forenoon (FN) and/or afternoon (AN) parts of the day were considered as a single data set and the average spectral AODs were retrieved for that data set following the Langley plot technique. The long term temporal stability of the Langley intercept (also called zero air mass intercept), corrected for the daily variation of the sun-earth distance was used as an indirect calibration of the instrument. During the study period, the long-term stability of the instrument has been fairly good, with the Langley intercepts lying within $10 \%$ of the mean for the worst cases. There were very few days (when significant deviations were observed associated with highly hazy conditions) that were not considered in further analysis. Estimates have shown that typical error in the retrieved value of $\tau_{\mathrm{p} \lambda}$ lies in the range $\sim 0.009-0.011$ at different wavelengths excluding the variance of the Langley fit (Moorthy et al. 1998). The small variance of the Langley intercept $(<10 \%)$ along with the other uncertainties in the estimation of $\tau_{\mathrm{p} \lambda}$, puts the uncertainty in the range of 0.03 0.05 at different wavelengths, with the higher values at shorter wavelengths $(<0.5 \mu \mathrm{m})$ and during high AODs $(>0.5)$. More details on the MWR including analysis details and 
error budget are given in several earlier papers (Moorthy et al. 1997, 1999, 2001; Satheesh and Moorthy 1997; Sagar et al. 2004; Saha et al. 2005).

\section{DATA USAGE AND METHOD OF ANALYSIS}

\subsection{Aerosol Size Distribution}

The observational database comprises of 475 sets of data (considering forenoon and afternoon as individual data sets) in 337 clear/partly clear days during the period from October 2001 to February 2006. Using the extensive estimates of $\tau_{\mathrm{p} \lambda}$ at ten wavelengths, the columnar (height integrated) size distribution function $\left[n_{\mathrm{c}}(r)\right]$ of aerosols have been determined by numerical inversion of Mie integral equation

$\tau_{\mathrm{p} \lambda}=\int_{r_{\mathrm{a}}}^{r_{\mathrm{b}}} \pi r^{2} Q_{\mathrm{ext}}(m, r, \lambda) n_{\mathrm{c}}(r) d r$

where $Q_{\text {ext }}$ is the aerosol extinction efficiency factor, which depends on the aerosol refractive index $(m)$, radius $(r)$, and wavelength of incident radiation $(\lambda)$, and $r_{\mathrm{a}}$ and $r_{\mathrm{b}}$ are, respectively, the lower and upper radii limits for integration. The quantity $n_{\mathrm{c}}(r)$ is given by:

$n_{\mathrm{c}}(r)=\int_{0}^{\alpha} n(r, z) d z$

which represents the number of particles per unit area per unit radius interval in a vertical column through the atmosphere. Equation (1) is solved following the iterative inversion procedure described by King (1982) and as applied by Moorthy et al. (1997). The values of $r_{\mathrm{a}}$ and $r_{\mathrm{b}}$ are taken as 0.05 and $3.0 \mu \mathrm{m}$, respectively, as they are found to be optimal by examining the kernel functions [integrand of Eq. (1)], corresponding to the extreme wavelengths used in the MWR observation. The complex refractive index depends on the chemical composition of aerosols and is different for different types of aerosols. Refractive index values as a function of wavelength are available in literature for different types of aerosols (e.g., Shettle and Fenn 1979; d'Almeida et al. 1991). We used wavelength dependent complex refractive index given by Lubin et al. (2002).

In order to quantify the observed changes in the retrieved size distributions in terms of physical parameters of the aerosols, the individual size distributions are characterized using appropriate analytical functions. Whenever the columnar size distributions indicated presence of two modes, the physical parameters such as mode radii $\left(r_{\mathrm{mi}}\right)$ and standard deviations $\left(\sigma_{\mathrm{i}}\right)$ are determined by least square fitting a bimodal lognormal distribution of the form: $n_{\mathrm{c}}(r)=\sum_{i=1}^{2} \frac{N_{0 i}}{\sqrt{2 \pi} \sigma_{i} r} \exp \left[-\frac{\left(\ln r-\ln r_{\mathrm{mi}}\right)^{2}}{2 \sigma_{i}^{2}}\right]$

where, $i=1$ represents the primary (small particle) and $i=$ 2 , the secondary (large particle) modes and $N_{\mathrm{oi}}$ is a scaling parameter which depends on the total aerosol concentration. Whenever the size distributions indicate the presence of a single mode only, the same function [Eq. (3) above] has been used to characterize it with $i=1$. For size distribution with a secondary large particle mode preceded by an inverse power-law type of behavior with no indication of primary mode, Eq. (3) is replaced by:

$n_{\mathrm{c}}(r)=N_{01} r^{-v}+\frac{N_{02}}{\sqrt{2 \pi} \sigma_{2} r} \exp \left[-\frac{\left(\ln r-\ln r_{\mathrm{m} 2}\right)^{2}}{2 \sigma_{2}^{2}}\right]$

where $v$ is the power-law index. In case, when the aerosol size distribution shows power law dependence, it is fitted with the equation:

$n_{\mathrm{c}}(r) d r=K r^{-v} d r$

or,

$\ln n_{\mathrm{c}}(r)=\ln K-v \ln r$

The normalization constant $K$ is adjusted to evolve the best fit.

By evolving a fit between the retrieved size distributions and the appropriate analytical functions [Eqs. (3) - (5)] with minimum rms error, the mode radii $\left(r_{\mathrm{m} 1}\right.$ and $\left.r_{\mathrm{m} 2}\right)$, standard deviations $\left(\sigma_{1}\right.$ and $\left.\sigma_{2}\right)$ and power law index $(v)$ are deduced for the CSDs. The other physical parameters of size distributions [viz., integrated content of aerosols $\left(N_{\mathrm{t}}\right)$ and effective radii $\left.\left(R_{\text {eff }}\right)\right]$ are estimated, following the expressions:

$N_{\mathrm{t}}=\int_{r_{\mathrm{a}}}^{r_{\mathrm{b}}} n_{\mathrm{c}}(r) d r$
$R_{\mathrm{eff}}=\frac{\int_{r_{\mathrm{a}}}^{r_{\mathrm{b}}} r^{3} n_{\mathrm{c}}(r) d r}{\int_{r_{\mathrm{a}}}^{r_{\mathrm{b}}} r^{2} n_{\mathrm{c}}(r) d r}$

\subsection{Meteorology and Trajectory Analysis}

Supplementary meteorological data during the period of observation were obtained from the India Meteorological Department (IMD) at Dibrugarh. 
The back-trajectories are calculated using the Hybrid Single Particle Legrangian Integrated Trajectory (HYSPLIT, http://www.arl.noaa.gov/ready/hysplit4.html) model (Draxler and Hess 1997) of National Oceanic and Atmospheric Administration (NOAA). As $\tau_{\mathrm{p} \lambda}$ is a measure of the columnar aerosol content, we have considered three height levels keeping in mind the elevated topography of the northeastern region over the observation site: $1000 \mathrm{~m}$ (within Atmospheric Boundary Layer, ABL), $2000 \mathrm{~m}$ (above ABL) and $3500 \mathrm{~m}$ (in the lower free troposphere; Moorthy et al. 2003) above ground level (AGL).

\section{RESULTS AND DISCUSSION}

\subsection{Number Size Distribution}

The representative CSDs for each season of the study period have been obtained by inverting the seasonal mean $\tau_{\mathrm{p} \lambda}$ values. A summary of the seasonal size distributions in terms of physical parameters of aerosols is given in Table $1\left(r_{\mathrm{m} 1}\right.$, $r_{\mathrm{m} 2}, \sigma_{1}$, and $\left.\sigma_{2}\right)$ and Table $2\left(\tau_{\mathrm{p} \lambda}, R_{\mathrm{eff}}, N_{\mathrm{t}}, N_{\mathrm{c}}, N_{\mathrm{a}}\right.$, and $\left.N_{\mathrm{c}} / N_{\mathrm{a}}\right)$. The symbols W, Pre-M, M, and Ret-M are used to represent the four seasons of winter (December - February), pre-monsoon (March - May), monsoon (June - September) and re- treating monsoon (October - November) season, respectively. Except Pre-M 2005, the entire seasonal size distributions are bimodal with the primary mode occurring at $r_{\mathrm{m} 1} \sim$ $0.04-0.17 \mu \mathrm{m}$ and the secondary mode at $r_{\mathrm{m} 2} \sim 0.88-1.29 \mu \mathrm{m}$. The primary mode is, in general, broader $\left(\sigma_{1} \sim 0.27-0.46\right)$ consistently, whereas the secondary mode is sharper $\left(\sigma_{2} \sim\right.$ $0.14-0.31)$. However, the mode radii and standard deviations do not show significant seasonal variations except random fluctuations about the mean. The Pre-M 2005 represents unimodal distribution with primary mode radii at $r_{\mathrm{m} 1} \sim$ $0.12 \mu \mathrm{m}$ and its standard deviation $\sigma_{1} \sim 0.66$.

Table 2 indicates that AODs are highest in pre-monsoon season, during which $R_{\text {eff }}$ also remains higher. But, $N_{\mathrm{t}}$ is relatively featureless. As $R_{\text {eff }}$ is the ratio of total volume to the area of aerosols, the seasonal variation of $R_{\text {eff }}$ are indicative of the seasonal changes in the relative dominance of larger to smaller particles. This aspect is examined by dividing $N_{\mathrm{t}}$ into two size regimes, e.g., the accumulation regime (small aerosols) and the coarse particle regime (large aerosols) considering $r=0.5 \mu \mathrm{m}$ as a cut off that divides the size distributions into the two distinct regimes. Then the total concentration of accumulation mode particles $\left(N_{\mathrm{a}}\right)$ and coarse particles $\left(N_{\mathrm{c}}\right)$ have been estimated as:

Table 1. Summary of seasonal size distributions along with the values of mode radii and standard deviations.

\begin{tabular}{|c|c|c|c|c|c|c|c|}
\hline \multirow{2}{*}{ Month } & \multirow{2}{*}{$\begin{array}{c}\text { Number of } \\
\text { Measurements }\end{array}$} & \multirow{2}{*}{$\begin{array}{c}\text { Nature of } \\
\text { Size-Distribution }\end{array}$} & \multicolumn{3}{|c|}{ Primary mode } & \multicolumn{2}{|c|}{ Secondary mode } \\
\hline & & & $v$ & $r_{\mathrm{m} 1}(\mu \mathrm{m})$ & $\sigma_{1}$ & $r_{\mathrm{m} 2}(\mu \mathrm{m})$ & $\sigma_{2}$ \\
\hline Ret-M 2001 & 30 & $\mathrm{BM}$ & & 0.07 & 0.45 & 1.20 & 0.24 \\
\hline W 2002 & 44 & $\mathrm{BM}$ & & 0.07 & 0.46 & 0.99 & 0.19 \\
\hline Pre-M 2002 & 11 & $\mathrm{BM}$ & & 0.08 & 0.37 & 0.88 & 0.21 \\
\hline M 2002 & 11 & $\mathrm{BM}$ & & 0.09 & 0.37 & 1.01 & 0.16 \\
\hline Ret-M 2002 & 24 & BM & & 0.05 & 0.45 & 0.86 & 0.25 \\
\hline W 2003 & 24 & $\mathrm{BM}$ & & 0.17 & 0.27 & 0.97 & 0.24 \\
\hline Pre-M 2003 & 24 & BM & & 0.16 & 0.33 & 1.09 & 0.31 \\
\hline M 2003 & 12 & BM & & 0.08 & 0.38 & 1.01 & 0.18 \\
\hline Ret-M 2003 & 29 & $\mathrm{BM}$ & & 0.08 & 0.45 & 0.97 & 0.19 \\
\hline W 2004 & 48 & $\mathrm{BM}$ & & 0.04 & 0.36 & 1.29 & 0.27 \\
\hline Pre-M 2004 & 25 & $\mathrm{BM}$ & & 0.12 & 0.36 & 0.93 & 0.22 \\
\hline M 2004 & 6 & $\mathrm{BM}$ & & 0.04 & 0.40 & 1.04 & 0.14 \\
\hline Ret-M 2004 & 27 & $\mathrm{BM}$ & & 0.09 & 0.43 & 0.97 & 0.20 \\
\hline W 2005 & 44 & $\mathrm{BM}$ & & 0.16 & 0.37 & 1.17 & 0.31 \\
\hline Pre-M 2005 & 14 & UM & & 0.12 & 0.66 & - & - \\
\hline M 2005 & 23 & $\mathrm{BM}$ & & 0.07 & 0.42 & 1.05 & 0.18 \\
\hline Ret-M 2005 & 38 & $\mathrm{BM}$ & & 0.07 & 0.45 & 0.99 & 0.18 \\
\hline W 2006 & 41 & BM & & 0.16 & 0.32 & 1.01 & 0.30 \\
\hline
\end{tabular}


Table 2. Physical parameters of seasonal size distributions over Dibrugarh.

\begin{tabular}{lcccccc}
\hline Month & $\tau_{\mathrm{p} \lambda}(\mathbf{0 . 5} \mu \mathbf{m})$ & $\boldsymbol{R}_{\text {eff }}(\mu \mathbf{m})$ & $\boldsymbol{N}_{\mathbf{t}}\left(\mathbf{1 0}^{\mathbf{1 2}} \mathbf{m}^{-\mathbf{2}}\right)$ & $\boldsymbol{N}_{\mathbf{c}}\left(\mathbf{1 0}^{\mathbf{1 0}} \mathbf{m}^{-\mathbf{2}}\right)$ & $\boldsymbol{N}_{\mathrm{a}}\left(\mathbf{1 0}^{\mathbf{1 3}} \mathbf{m}^{-\mathbf{2}}\right)$ & $\boldsymbol{N}_{\mathrm{c}} / \mathbf{N}_{\mathrm{a}}\left(\mathbf{1 0}^{-\mathbf{2}} \mathbf{m}^{-\mathbf{2}}\right)$ \\
\hline Ret-M 2001 & $0.14 \pm 0.01$ & 0.45 & 1.87 & 0.36 & 0.187 & 0.19 \\
W 2001 - 2002 & $0.30 \pm 0.08$ & 0.22 & 7.35 & 0.80 & 0.73 & 0.11 \\
Pre-M 2002 & $0.36 \pm 0.12$ & 0.34 & 5.79 & 2.64 & 0.57 & 0.45 \\
M 2002 & $0.28 \pm 0.04$ & 0.36 & 3.28 & 1.39 & 0.32 & 0.42 \\
Ret-M 2002 & $0.14 \pm 0.04$ & 0.28 & 5.23 & 1.15 & 0.52 & 0.22 \\
W 2002 - 2003 & $0.32 \pm 0.06$ & 0.31 & 1.17 & 0.64 & 0.11 & 0.55 \\
Pre-M 2003 & $0.48 \pm 0.04$ & 0.51 & 1.39 & 1.09 & 0.13 & 0.78 \\
M 2003 & $0.15 \pm 0.05$ & 0.54 & 1.04 & 0.98 & 0.10 & 0.94 \\
Ret-M 2003 & $0.22 \pm 0.01$ & 0.31 & 2.55 & 0.85 & 0.25 & 0.33 \\
W 2003 - 2004 & $0.21 \pm 0.04$ & 0.10 & 73.4 & 0.28 & 7.34 & 0.01 \\
Pre-M 2004 & $0.43 \pm 0.07$ & 0.44 & 1.81 & 2.39 & 0.17 & 1.34 \\
M 2004 & $0.18 \pm 0.12$ & 0.15 & 2.73 & 0.91 & 2.73 & 0.03 \\
Ret-M 2004 & $0.19 \pm 0.03$ & 0.41 & 1.34 & 0.96 & 0.13 & 0.70 \\
W 2004 - 2005 & $0.32 \pm 0.07$ & 0.61 & 6.91 & 0.59 & 0.06 & 0.87 \\
Pre-M 2005 & $0.56 \pm 0.13$ & 0.50 & 1.76 & 3.10 & 0.17 & 1.79 \\
M 2005 & $0.24 \pm .0 .11$ & 0.27 & 1.15 & 0.96 & 1.15 & 0.08 \\
Ret-M 2005 & $0.20 \pm 0.03$ & 0.38 & 3.45 & 1.27 & 0.34 & 0.37 \\
W 2005 - 2006 & $0.32 \pm 0.08$ & 0.38 & 1.04 & 0.62 & 0.10 & 0.61 \\
\hline
\end{tabular}

$N_{\mathrm{a}}=\int_{r_{\mathrm{a}}}^{0.5} n_{\mathrm{c}}(r) d r$

$N_{\mathrm{c}}=\int_{0.5}^{r_{\mathrm{b}}} n_{\mathrm{c}}(r) d r$

From this a dimensionless ratio $N_{\mathrm{c}} / N_{\mathrm{a}}$ is evaluated, which represents a measure of the relative abundance of the large (coarse) particles to the total aerosol concentration. This is so because $N_{\mathrm{c}}$ is generally about 2 to 4 orders smaller than $N_{\mathrm{a}}$, so that $N_{\mathrm{a}}$ is approximately equal to $N_{\mathrm{t}}$. It is found that the ratio of $N_{\mathrm{c}} / N_{\mathrm{a}}$ increases during pre-monsoon seasons, indicating increased abundance of large particles in the size spectrum.

The characteristic variation of columnar size distribution with season is further investigated by obtaining a single size distribution for each season from the ensemble mean $\tau_{\mathrm{p} \lambda}$ values, irrespective of the year. The representative size distributions at four seasons are shown in Fig. 2. The seasonal mean values of $\tau_{\mathrm{p} \lambda}$ at $0.5 \mu \mathrm{m}$ and $R_{\text {eff }}$ are also shown in the figure. It is seen that all the distributions are bimodal with the primary mode being more prominent in pre-monsoon and winter. The primary mode is broader $\left(\sigma_{\text {mean }} \sim 0.45 \pm\right.$

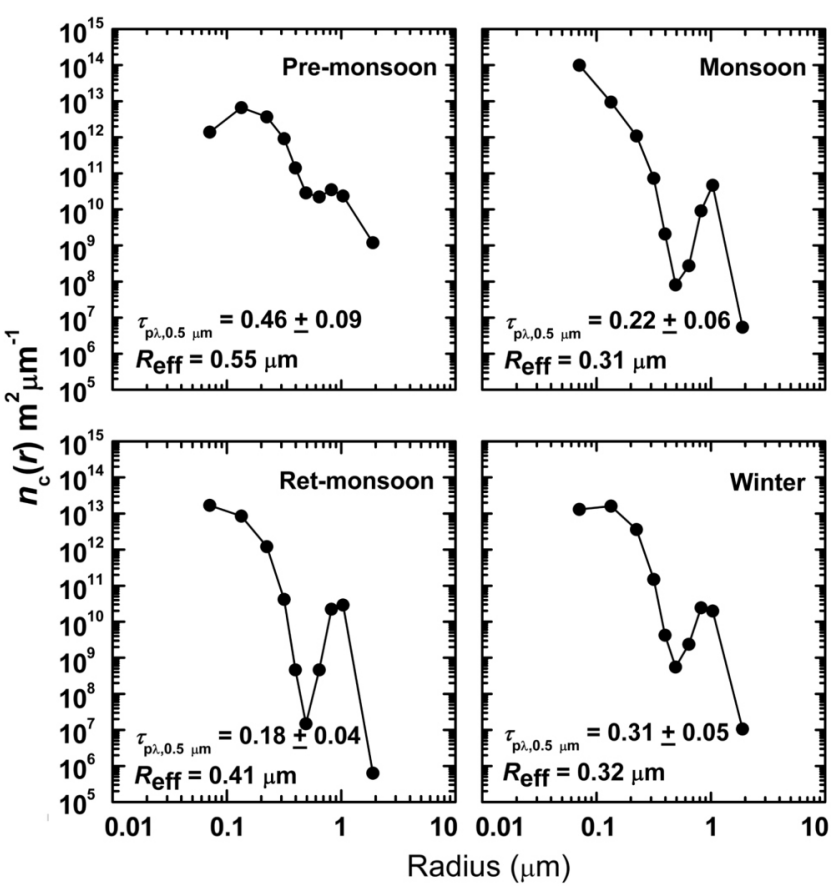

Fig. 2. Mean seasonal columnar size distributions at four different seasons (Pre-Monsoon, Monsoon, Ret-Monsoon, and Winter) along with the values of aerosol optical depth at $0.5 \mu \mathrm{m}\left(\tau_{\mathrm{p} \lambda, 0.5 \mu \mathrm{m}}\right)$ and effective radius $\left(R_{\text {eff }}, \mu \mathrm{m}\right)$ embedded in the figure. 
0.04) in all the cases and appears in the extreme end of shorter radii $\left(r_{\mathrm{m} 1} \sim 0.09 \pm 0.03 \mu \mathrm{m}\right)$. The highest value of $\tau_{\mathrm{p} \lambda}$ at $0.5 \mu \mathrm{m}(\sim 0.46 \pm 0.09)$ and $R_{\text {eff }}(\sim 0.55 \mu \mathrm{m})$ in the premonsoon season indicates the maximum abundance of large particles during this season.

Despite the seasonal characteristics of CSDs corresponding to seasonal mean $\tau_{\mathrm{p} \lambda}$, the monthly characteristics of CSDs are also analyzed for each month of MWR observation, as $\tau_{\mathrm{p} \lambda}$ showed distinct monthly variations. Thus a total of 41 sets of monthly mean AODs are inverted to obtain the representative CSDs for different months. The unavailable monthly analyses are due to the unavailability of MWR observations due to cloudy and rainy weather. The CSDs for all the available months except for the months of April 2003 and February, June and September in 2005 are bimodal. Out of these five months, the month of April 2003 represents power law distribution with $v=3$.9. The size distributions during the month of February, June, and September in 2005 are unimodal with mode radii occurring at $\sim 0.16 \pm 0.61$, $0.08 \pm 0.61$, and $0.11 \pm 0.58 \mu \mathrm{m}$, respectively. The back-trajectory analysis indicates that only the free tropospheric trajectories, for a few days in the month of April 2003, were originated from the western Indian landmass. But, the trajectories at other two (lower) levels were lying inside the high hills and mountain barriers of northeast India. Similarly, the synoptic air masses were absent during the months of February, June, and September 2005, which may be the cause for the elimination of secondary mode in the retrieved CSDs due to a lack of long range transport coupled with strong wet removal during June and September 2005. The influence of long-range transport to the growth of aerosols over Dibrugarh is discussed in section 4.2 in detail. On the other hand, the bimodal distributions are, in general, the combination of two unimodal distributions and in most cases, the primary mode is not well developed, but is only indicated by the slanting nature of the distribution. This is because of the fact that the primary mode (small particle) falls below $r_{\mathrm{a}}$ (although it is close to it). However the secondary mode (large particle) is clearly seen in all the cases. The bimodal distributions in the months of July and September 2003 and July 2005 are the combination of a power law and a unimodal distribution.

In order to investigate the temporal features of the physical characteristics of aerosols, the estimated values of $r_{\mathrm{m} 1}$, $r_{\mathrm{m} 2}, \sigma_{1}, \sigma_{2}, R_{\mathrm{eff}}, N_{\mathrm{t}}$, and $N_{c} / N_{a}$ for each month of the study period are shown in Figs. 3 and 4, respectively. No systematic variations are seen for mode radii and standard deviation except for some random fluctuations about the mean (Fig. 3). The ensembles mean value of $r_{\mathrm{m} 1}$ and $r_{\mathrm{m} 2}$ are $0.11 \pm 0.03$ and $0.99 \pm 0.09$ and the corresponding $\sigma_{1}$ and $\sigma_{2}$ are $0.41 \pm 0.09$ and $0.21 \pm 0.06$, respectively. The standard deviation in the primary mode is higher than the secondary mode, which indicates that the primary mode is broader and occurs at more different values of $r_{\mathrm{m} 1}$ compared to the secondary mode,
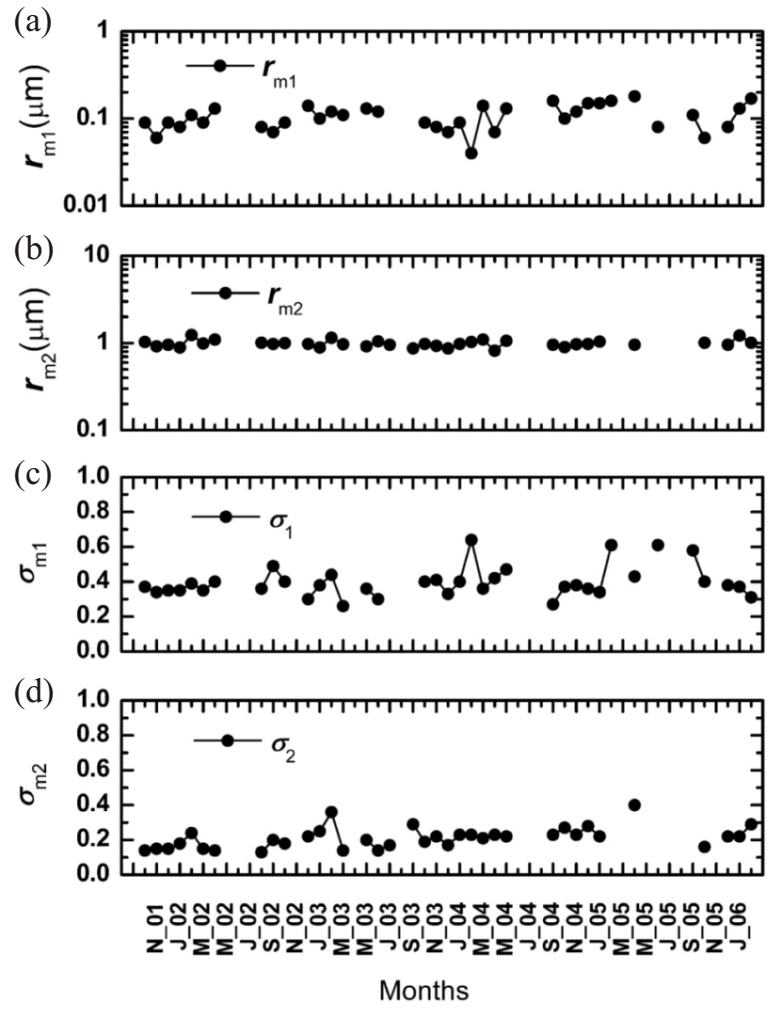

Fig. 3. Monthly variation of (a) primary, $r_{\mathrm{m} 1}$ and (b) secondary, $r_{\mathrm{m} 2}$ mode radii and standard deviation of the (c) primary mode, $\sigma_{1}$ and (d) secondary mode, $\sigma_{2}$ respectively.
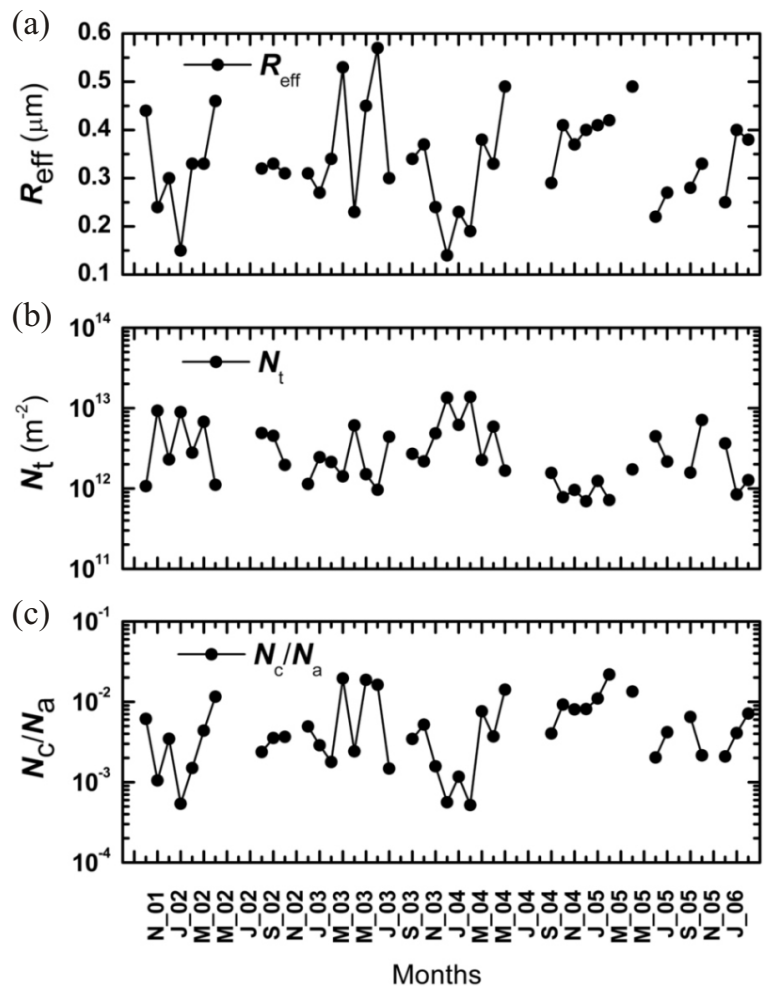

Fig. 4. Monthly variation of (a) effective radius $\left(R_{\text {eff }}, \mu \mathrm{m}\right)$, (b) integrated content of aerosols $\left(N_{\mathrm{t}}, \mathrm{m}^{-2}\right)$, and (c) the ratio of coarse to accumulation mode $\left(N_{\mathrm{c}} / N_{\mathrm{a}}\right)$ particles. 
which is sharper and consisted. It is seen from the Fig. 4a that $R_{\text {eff }}$ are high during March/April (or May) months, whereas $N_{\mathrm{t}}$ is relatively featureless (Fig. 4b) similar to that seen in the seasonal analysis. However, the ratio of $N_{\mathrm{c}} / N_{\mathrm{a}}$ (Fig. 4c) indicates significant increase in the relative abundance of large particles in the month of March, April or May. Since $N_{\mathrm{a}}$ constitutes about $99 \%$ of the total content, variations in $N_{\mathrm{c}}$ may not be reflected in $N_{\mathrm{t}}$. It is readily seen from Figs. $4 \mathrm{~b}$ and c that month-to-month variations in $N_{\mathrm{t}}$ and $N_{\mathrm{c}} / N_{\mathrm{a}}$ are mirror images of each other.

The foregoing discussions clearly indicate that the physical parameters of aerosols representing the physical state of aerosols are highly variable over different months or seasons and the CSDs are found to fall under three broad categories. The characteristics distributions (namely unimodal, bimodal, and power law) at three different months are shown in Figs. 5 - 7. Ideally, the unimodal size distribution is characterized by a single mode (peak) in the columnar number density-size spectrum with the number density dropping off on either side of the peak. The peak occurs generally in the size range of 0.05 to $0.4 \mu \mathrm{m}$. However, it is found that, in the present study, the decrease in columnar number density on the shorter radii side of the peak is not present in some distributions. In such cases, the columnar number density remains more or less constant at shorter radii. Probably the peak is quite broad in these cases. On some occasions, the primary mode is not seen explicitly. Instead, the columnar number density decreases with increase in radius from a maximum value. In such cases, the primary mode may be assumed to occur at still smaller radii $(r<0.05 \mu \mathrm{m})$ and cannot be seen

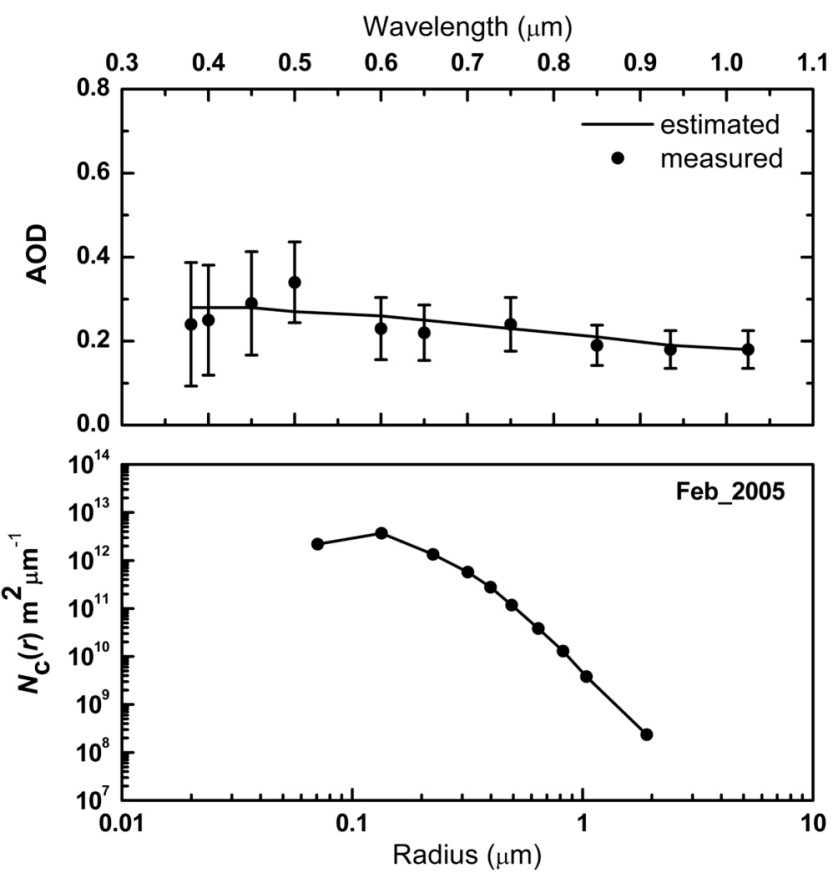

Fig. 5. Characteristic unimodal (UM) distribution deduced from the monthly mean $\tau_{\mathrm{p} \lambda}$ values for the month of February 2005. in the inverted distributions since the distributions are defined for $r>0.05 \mu \mathrm{m}$ due to the restriction imposed by the wavelengths used in the MWR. Moreover, on the smaller radii side $(r<0.05 \mu \mathrm{m})$ the number density cannot increase indefinitely with decrease in radius because processes like coagulation will lead to formation of a mode in the small particle regime (Junge 1963; Pruppacher and Klett 1978). The unimodal distribution, shown in Fig. 5 representing the month of February 2005 depict $r_{\mathrm{m} 1} \sim 0.17 \mu \mathrm{m}$ with the columnar number density falling off rapidly on larger particles. At the peak, the columnar number density is of the order of $\sim 10^{12} \mathrm{~m}^{-2} \mu \mathrm{m}^{-1}$. The respective $\tau_{\mathrm{p} \lambda}-\lambda$ plot is shown in the top panel of the figure along with the re-estimated values of $\tau_{\mathrm{p} \lambda}$. In this case the black circles represent the measured $\tau_{p \lambda}$ values with the vertical bars on them showing the measurement errors. The continuous line correspond to the $\tau_{\mathrm{p} \lambda}$ re-estimated using the inverted size distribution by using Eq. (3). The bimodal distribution essentially depicts a secondary mode occurring at radius $r>0.5 \mu \mathrm{m}$ and having a peak number density about two orders less than that at the primary mode. The columnar number density first decreases with increase in radius from a maximum value (primary mode), reaches a trough followed by the secondary mode $\left(r_{\mathrm{m} 2} \sim 0.9 \mu \mathrm{m}\right)$ with the number density dropping off at larger radii. The representative bimodal distribution obtained in the month of September 2004, shown in Fig. 6, indicates that the columnar number density falls off the peak rapidly as particle size increases. Occasionally, the columnar number density also showed a monotonic decrease with increase in the particle radius depicting inverse power law dependence with particle

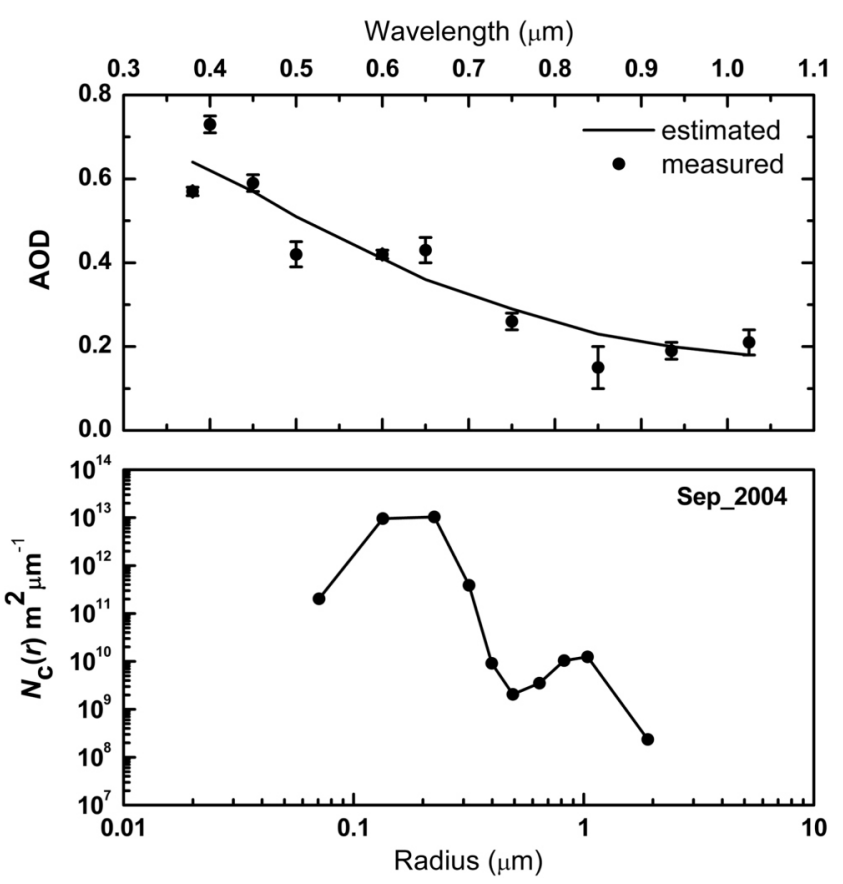

Fig. 6. Characteristic bimodal (BM) distribution deduced from the monthly mean $\tau_{\mathrm{p} \lambda}$ values for the month of September 2004 . 


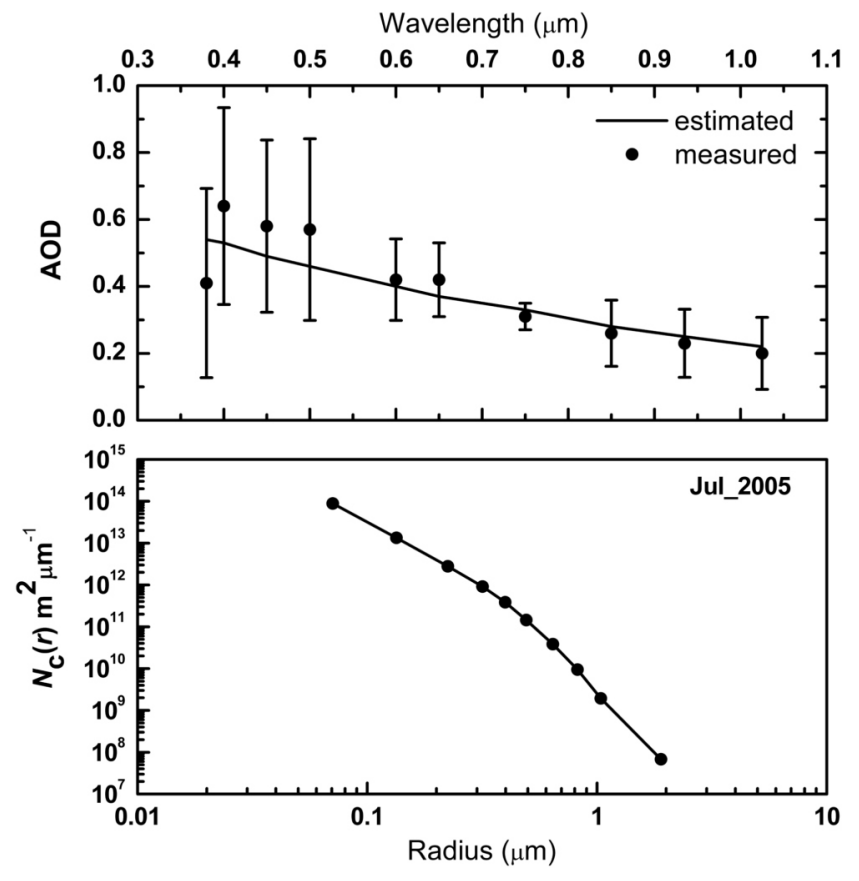

Fig. 7. Characteristic power law (PL) distribution deduced from the monthly mean $\tau_{\mathrm{p} \lambda}$ values for the month of July 2005 .

radius and exhibiting a power law or Junge distribution. The example of power law distribution, obtained in the month of July 2005 (Fig. 7), shows a more or less monotonic decrease in aerosol number density (columnar) with increase in the particle radius. The columnar number density decreases from $\sim 10^{13} \mathrm{~m}^{-2} \mu \mathrm{m}^{-1}$ to $10^{7} \mathrm{~m}^{-2} \mu \mathrm{m}^{-1}$ in the radius interval 0.05 to $3 \mu \mathrm{m}$. This type of distribution is, in general, rare at Dibrugarh.

The wavelength dependence of $\tau_{\mathrm{p} \lambda}$ resulting in unimodal distribution on inversion (as shown in Fig. 5) is distinctly different from that resulting in bimodal distribution (Fig. 6). The $\tau_{\mathrm{p} \lambda}-\lambda$ plots depict a negative curvature in the case of unimodal distribution, whereas the curvature is positive towards the longer wavelength in the case of bimodal distribution. There is almost linear decrease of $\tau_{\mathrm{p} \lambda}$ with $\lambda$ in the case of power law distribution (Fig. 7). Each of the size distribution exhibits characteristic wavelength dependence of aerosol optical depths.

\subsection{Investigation of Source Areas}

To investigate the influence of long-range transport from different source regions to the site of MWR station at Dibrugarh, the 5-day isobaric back trajectories for all the days on which the AOD data available are analyzed. The 5 -day period was considered in view of the typical residence time of $\geq 1$ week for aerosol in the lower troposphere (Ramanathan et al. 2001) during the dry period. The trajectories essentially back-trace the course of aerosol parcels in space (latitude, longitude, and altitude) and time (days), starting from the source of investigation at a particular height from the ground. Trajectories are assigned to a particular sector if they reside over it for more than $80 \%$ of their travel time before reaching the observation site. Based on this, similar trajectories are grouped into a particular sector according to their direction of flow, namely West (W), Southwest (SW), Southeast (SE), North (N), and Local (L) at four seasons of Pre-M (March - May), M (June - September), Ret-M (October - November), and W (December - February) separately. The west sector (W) include the trajectories originating from west Asian regions, north and middle and the west coast of India and then flowing over the Indian landmass, across the Himalayan Mountains and partly over the southern Chinese region. The trajectories having a significant Bay-of-Bengal signature before reaching northeast India and finally the observation point (Dibrugarh) are included in southwest sector (SW). The trajectories originating from southeastern locations such as Thailand and Myanmar belong to the southeast sector (SE). Within the northern (N) sector, the trajectories originate from the southern Chinese region situated towards the north of Dibrugarh. Lastly, when all the trajectories confine to the boundary of northeastern India, they are considered to lie within the local sector (L). In classifying the trajectories into a particular group it is considered that at least two of the trajectories out of three height levels had traversed the particular region represented by different sectors. Subsequent to this classification, the spectral AOD values along with the corresponding values of Angstrom exponent $\alpha$ and turbidity coefficient $\beta$ for each observation day are separated and averaged with respect to each trajectory group at different seasons. The parameter $\alpha$ is a good indicator of the fraction of accumulation mode particles to coarse mode, while $\beta$ represents a measure of columnar aerosol loading in the atmosphere. Both these parameters are related through Ångström equation as (Ångström 1961):

$\tau_{\mathrm{p} \lambda}=\beta \lambda^{-\alpha}$

Values of $\alpha \leq 1$ indicate size distributions dominated by coarse mode aerosols (radii $\geq 0.5 \mu \mathrm{m}$ ) that are typically associated with dust and sea salt, and values of $\alpha \geq 2$ indicate size distributions dominated by fine mode aerosols (radii $\leq 0.5 \mu \mathrm{m}$ ) that are usually associated with urban pollution and biomass burning (Eck et al. 1999; Schuster et al. 2006). The values of $\alpha$ and $\beta$ are evaluated by evolving a least square linear fit between $\tau_{\mathrm{p} \lambda}$ and $\lambda$ in a $\log -\log$ scale. The slope of the regression line gives the value of $\alpha$ while $\beta$ is evaluated from the intercept.

The average values of $\tau_{\mathrm{p} \lambda}, \alpha$, and $\beta$ with respect to each trajectory group are given in Table 3 along with the values of their standard deviations (values appearing after ' \pm ' symbol). The percent contributions of different trajectory groups are given in the last column of the table, which indicate that 
Table 3. Distribution of $\tau_{\mathrm{p} \lambda}, \alpha$, and $\beta$ with respect to each trajectory groups.

\begin{tabular}{|c|c|c|c|c|c|c|}
\hline Season & Group & Wind sectors & $\tau_{\mathrm{p} \lambda}$ at $0.5 \mu \mathrm{m}$ & $\alpha$ & $\beta$ & Percent Contribution \\
\hline \multirow[t]{3}{*}{ Pre-M } & 1 & W & $0.49 \pm 0.25$ & $0.81 \pm 0.27$ & $0.28 \pm 0.14$ & $49 \%$ \\
\hline & 2 & SW & $0.55 \pm 0.41$ & $0.73 \pm 0.49$ & $0.33 \pm 0.22$ & $46 \%$ \\
\hline & 3 & $\mathrm{~N}$ & $0.31 \pm 0.08$ & $0.64 \pm 0.09$ & $0.18 \pm 0.08$ & $5 \%$ \\
\hline \multirow[t]{3}{*}{ M } & 1 & SW & $0.34 \pm 0.18$ & $0.88 \pm 0.53$ & $0.19 \pm 0.12$ & $57 \%$ \\
\hline & 2 & $\mathrm{E} / \mathrm{SE}$ & $0.13 \pm 0.08$ & $0.37 \pm 0.21$ & $0.08 \pm 0.03$ & $35 \%$ \\
\hline & 3 & $\mathrm{~L}$ & $0.32 \pm 0.14$ & $1.14 \pm 0.36$ & $0.14 \pm 0.05$ & $8 \%$ \\
\hline \multirow[t]{4}{*}{ Ret-M } & 1 & W & $0.24 \pm 0.17$ & $0.96 \pm 0.32$ & $0.14 \pm 0.05$ & $61 \%$ \\
\hline & 2 & SW & $0.19 \pm 0.15$ & $0.87 \pm 0.09$ & $0.11 \pm 0.06$ & $12 \%$ \\
\hline & 3 & $\mathrm{E} / \mathrm{SE}$ & $0.16 \pm 0.02$ & $0.87 \pm 0.31$ & $0.10 \pm 0.05$ & $7 \%$ \\
\hline & 4 & $\mathrm{~L}$ & $0.21 \pm 0.15$ & $0.92 \pm 0.27$ & $0.10 \pm 0.05$ & $20 \%$ \\
\hline \multirow[t]{4}{*}{ W } & 1 & $\mathrm{~W}$ & $0.33 \pm 0.20$ & $1.04 \pm 0.42$ & $0.16 \pm 0.11$ & $95 \%$ \\
\hline & 2 & $\mathrm{E} / \mathrm{SE}$ & $0.15 \pm 0.06$ & $0.88 \pm 0.47$ & $0.19 \pm 0.03$ & $2 \%$ \\
\hline & 3 & $\mathrm{~N}$ & $0.28 \pm 0.11$ & $1.01 \pm 0.19$ & $0.11 \pm 0.04$ & $1 \%$ \\
\hline & 4 & $\mathrm{~L}$ & $0.22 \pm 0.14$ & $0.87 \pm 0.22$ & $0.13 \pm 0.07$ & $2 \%$ \\
\hline
\end{tabular}

the transport was predominantly from the west during premonsoon, ret-monsoon, and winter season; while during monsoon season, the dominant sector was southwest (SW) contributing $57 \%$ of the total transport processes. However, the contribution of the SW sector is also significant during pre-monsoon season (46\%). Representatives of five-day back trajectories at 1000, 2000, and $3500 \mathrm{~m}$ above ground level for each season are shown in Fig. 8.

Back-trajectory analysis indicate that during pre-monsoon season, the highest average values of $\tau_{\mathrm{p} \lambda}(\sim 0.55 \pm 0.41)$ and $\beta(\sim 0.33 \pm 0.22)$ are related to the air masses from Bay-of-Bengal (SW-sector), along with comparable higher values of $\tau_{\mathrm{p} \lambda}(\sim 0.49 \pm 0.25)$ and $\beta(\sim 0.28 \pm 0.14)$ when the trajectories belong to the West (W) sector. The higher values of $\tau_{\mathrm{p} \lambda}$ and $\beta$, but lower $\alpha(<1.0)$ associated with both these sectors indicate significant advection of coarse mode particles till the onset of monsoon rain. Since, most of the trajectories, which belong to the West (W) and Southwest (SW) sector, flow across the major industrial and urban regions of Indo-Gangetic plains (Vinoj et al. 2004; Tripathi et al. 2005) and the peninsular region of the Bay-of-Bengal before entering into the Brahmaputra valley, they significantly advect continental and marine aerosols, apart from the advection of large amounts of desert and mineral aerosols from the west Asian and Indian deserts. In addition to advection by air masses, the increased solar heating (Fig. 9a) of the land mass over the lower plains adjacent to the site during the pre-monsoon season would result in increased convective mixing and elevation of the boundary layer aerosols.
During the monsoon season, the advection of marine aerosols from the Bay-of-Bengal ( $\mathrm{SW}$-sectors) is significant (57\%), which leads to high values of $\tau_{\mathrm{p} \lambda}(\sim 0.34 \pm 0.18)$ and $\beta(\sim 0.19 \pm 0.12)$ compared to that in the other two sectors. The contribution of the E/SE sector is not significant enough to enhance $\tau_{\mathrm{p} \lambda}$ or $\beta$, even though the percentage contribution of this sector is high (35\%). The higher value of $\alpha(>1.0)$ in

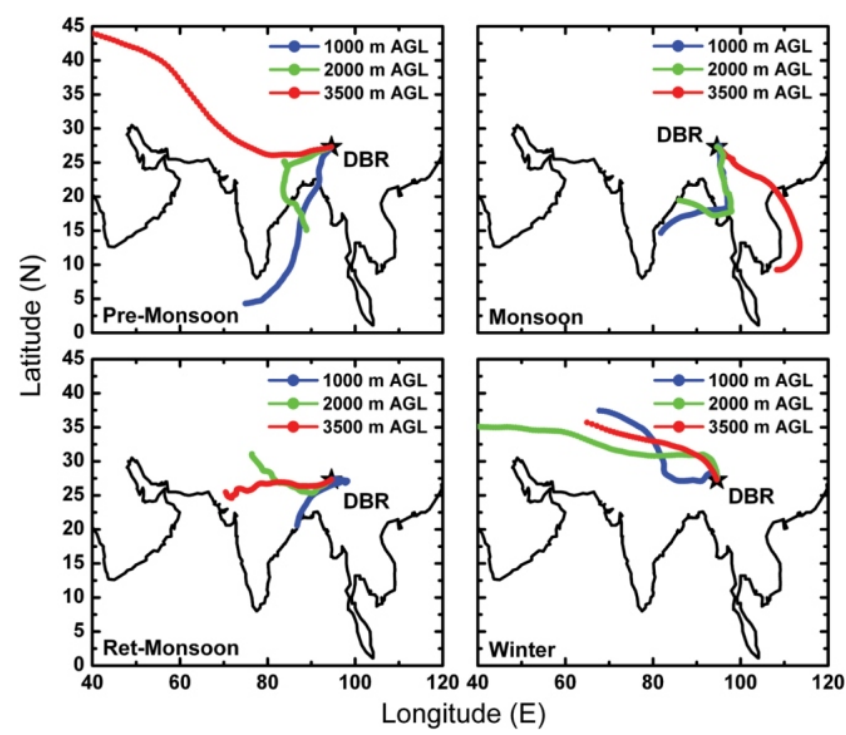

Fig. 8. Representative dominant trajectory types in four seasons of winter, pre-monsoon, monsoon, and ret-monsoon at three different height: 1000, 2000, and $3500 \mathrm{~m}$ above ground level (AGL). 

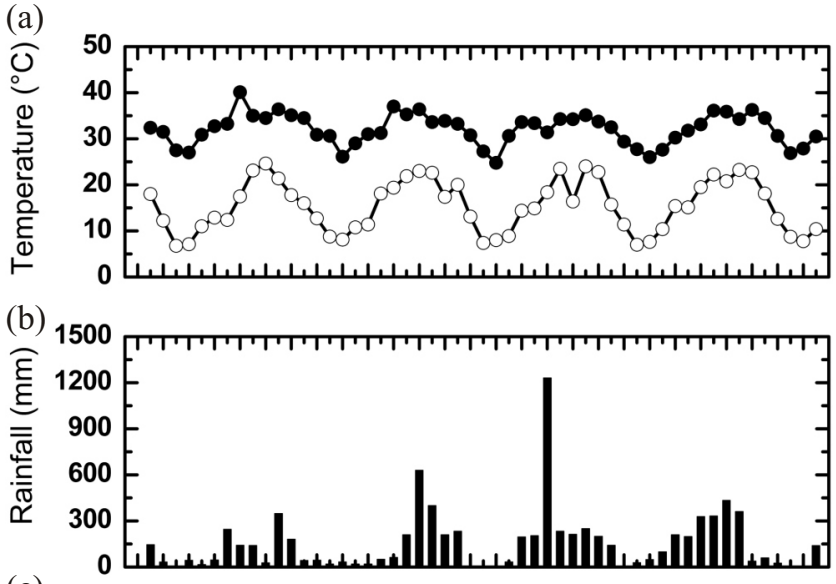

(c)

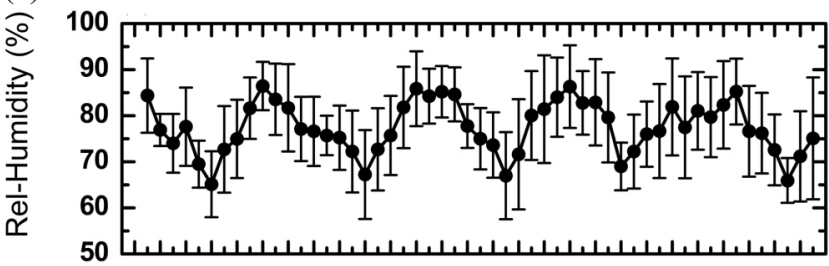

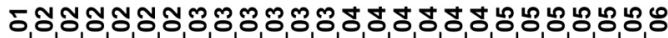

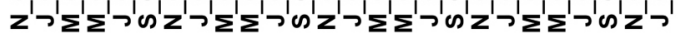

Months

Fig. 9. Monthly variation of (a) temperature $\left({ }^{\circ} \mathrm{C}\right)$, (b) rainfall $(\mathrm{mm})$, and (c) relative humidity (\%) at Dibrugarh during the period from October 2001 to February 2006.

the local sector indicates the abundance of fine mode aerosols, even though the percentage contribution of this sector is low $(8 \%)$. The intense rainfall during the monsoon season (June - September) (Fig. 9b) is the basic cause for the decrease in the abundance of both coarse as well as fine mode aerosols in the atmosphere.

During the ret-monsoon and winter season, most of the trajectories belong to the West sector, i.e., trajectories originating from west Asia move eastward and then pass over the Indian landmass. However the contributions of trajectories in this sector to enhance $\beta$ are not significant in both the retreating monsoon and winter. During October and November, the wash out by rain in the preceding months without sufficient replenishment could be the reason for lower aerosol loading in the atmosphere. Even though, the comparatively higher values of $\tau_{\mathrm{p} \lambda}$ and $\alpha(>1.0)$ indicate more advection of fine mode aerosols from the urbanized regions of the IndoGangetic plains during winter than that during the ret-monsoon season, the trajectory analyses do not provide any information on the transportation of coarse mode aerosols during both these seasons. As such, the occurrence of secondary mode in the columnar size distribution during both retreating monsoon and winter may be due to some local perturbations originating from forest and fossil fuel fires. During this period, the relative humidity decreases becoming lower in the winter season (Fig. 9c). Thus the atmosphere becomes dry and the banks of the mighty river Brahmaputra, which is not very far from the experimental station, look like great sandy plains. A moderate to high wind is capable of loosening and lifting the dust particles from these sandy areas. Also surrounding vegetation may make some contribution to the secondary mode of observed size distributions during this period as pollens and seeds, etc. are also important constituents of natural aerosols apart from windblown dust (silica).

\subsection{Effect of Surface Wind Speed}

Aerosol size distribution, which covers several orders of magnitude both in size and number concentration, results primarily from the effects of production, removal, and transport mechanisms. There are two basic production mechanisms namely gas-to-particle conversion and bulk-to-particle conversion (Jaenicke 1984; Hoppel et al. 1990). The particles are removed from their respective sizes by processes like coagulation, sedimentation, impaction scavenging and wet scavenging. The aerosol size distribution is controlled by the basic process of coagulation at the lower cut-off region $(r \sim 0.1 \mu \mathrm{m})$ and sedimentation and impaction scavenging at the higher side $(>0.5 \mu \mathrm{m})$. The behavior of the size distribution in between these cut off radii reflects the effects of aerosol sources, sinks and transport mechanisms, which are of regional importance. Close to the aerosol source, aerosol properties are associated with the generating mechanisms. But at large distances from the sources on a global or synoptic scale, aerosol characteristics change.

Earlier studies on the effect of the changes in wind speed on aerosol characteristics have indicated a significant increase in aerosol concentration (Lovett 1978; Hoppel et al. 1990; O'Dowd and Smith 1993), aerosol optical depth (Smirnov et al. 1994; Moorthy et al. 1997), and mass loading (Exton et al. 1985; Moorthy et al. 1997) with increase in wind speed. Exton et al (1985) also reported that the effect appears to be stronger at larger sizes. To examine the effect of wind speed on aerosol characteristics, we examine the variation of the ratio $\left(N_{\mathrm{c}} / N_{\mathrm{a}}\right)$ of the number concentrations of coarse particles $\left(N_{\mathrm{c}}\right)$ to the number concentration of accumulation mode particles $\left(N_{\mathrm{a}}\right)$ estimated from the respective size distributions against the mean wind speed during the period of MWR observation (Fig. 10). It is seen from the figure that the ratio $\left(N_{\mathrm{c}} / N_{\mathrm{a}}\right)$ increases with increase in wind speed with a moderate correlation coefficient $\mathrm{R} \sim 0.72$. This shows that the increase in surface wind speed over a remote continental location of natural background causes moderate increase in the relative dominance of coarse particles produced due to dry weather conditions.

\section{SUMMARY AND CONCLUSION}

From the investigation of aerosol size distribution properties, retrieved from spectral AOD estimates over Di- 


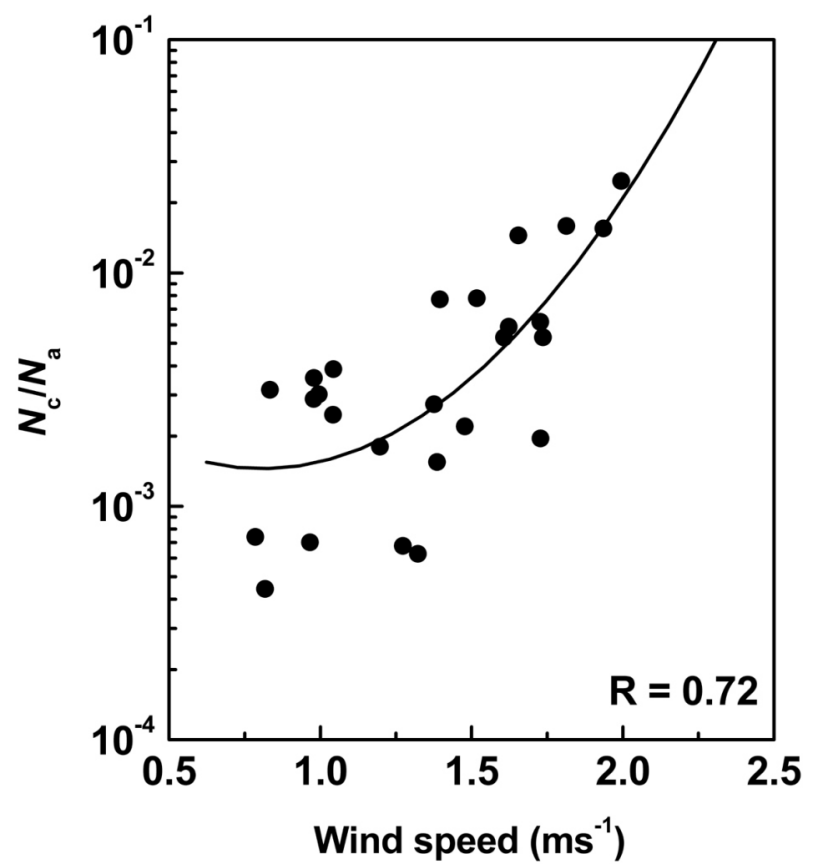

Fig. 10. The variation of the ratio of number of coarse $\left(N_{\mathrm{c}}\right)$ to accumulation $\left(N_{\mathrm{a}}\right)$ mode aerosols with mean wind speed. The points are deduced from the radiometer measurements and the curved line is the second order polynomial fit.

brugarh, the following conclusions are made:

i. The columnar size distributions are, in general, bimodal although unimodal distributions are seen in few cases. The power law distribution is seen only in the month of July 2005.

ii. The primary mode is not well developed in most of the cases, whereas the secondary mode is sharper and consistent for all the bimodal distributions.

iii. Higher values of AOD and $R_{\text {eff }}$ during pre-monsoon season are attributed to the increase in the relative dominance of coarse particles in the size spectrum.

iv. During pre-monsoon and monsoon season, the existence of secondary mode is due to the advection of coarse mode aerosols from the west Asian and Indian desert, Indian mainland, and the Bay-of-Bengal.

v. The local turbulence coupled with the sandy areas of the Brahmaputra River and the surrounding tea gardens influence the growth of secondary mode in the retrieved size distributions during ret-monsoon and winter season.

Acknowledgement This study was carried out under Indian Space Research Organization's Geosphere Biosphere Programme (ISRO-GBP). The authors humbly acknowledge the NOAA Air Resources Laboratory (ARL) for the provision of the HYSPLIT transport and dispersion model used in this paper.

\section{REFERENCES}

Anderson, T. L., R. J. Charlson, D. M. Winker, J. A. Ogren, and K. Holmén, 2003: Mesoscale variations of tropospheric aerosols. J. Atmos. Sci., 60, 119-136, doi: 10.1175/15200469(2003)060<0119:MVOTA >2.0.CO;2. [Link]

Ångström, A., 1961: Techniques of determining the turbidity of the atmosphere. Tellus, 13, 214-223.

d'Almeida, G. A., P. Koepke, and E. P. Shettle, 1991: Atmospheric Aerosols: Global Climatology and Radiative Characteristics. Deepak Publishing, Hampton, VA.

Derwent, R. G., D. R. Middleton, R. A. Field, M. E. Goldstone, J. N. Lester, and R. Perry, 1995: Analysis and interpretation of air quality data from an urban roadside location in central London over the period from July 1991 and July 1992. Atmos. Environ., 29, 923-946, doi: 10.1016/13522310(94)00219-B. [Link]

Draxler, R. R. and G. D. Hess, 1997: Description of the Hysplit_4 modeling system, NOAA Tech Memo ERL ARL224, Dec, 24.

Eck, T. F., B. N. Holben, J. S. Reid, O. Dubovik, A. Smirnov, N. T. O’Neill, I. Slutsker, and S. Kinne, 1999: Wavelength dependence of the optical depth of biomass burning, urban and desert aerosols. J. Geophys. Res., 104, 31333-31349, doi: 10.1029/1999JD900923. [Link]

Exton, H. J., J. Latham, P. M. Park, S. J. Perry, M. H. Smith, and R. R. Allan, 1985: The production and dispersal of marine aerosol. Quart. J. Roy. Meteor. Soc., 111, 817-837, doi: 10.1256/smsqj.46908. [Link]

Hansen, J. E., M. Sato, A. Lacis, R. Reddy, I. Tegen, and E. Mathews, 1998: Climate forcing in the Industrial era, Proc. Natl. Acad. Sci., 95, 12753-12758.

Hoppel, W. A. and G. M. Frick, 1990: Sub micron aerosol size distribution measured over the tropical and South pacific. Atmos. Environ., 24, 645-659.

Jaenicke, R., 1984: Physical aspects of atmospheric aerosol. In: Gerbard, H. E., A. Deepak, (Eds.), Aerosols and Their Climatic Effects, A. Deepak Publishing, Hampton, Virginia, USA, 7-34.

Jaenicke, R., 1993: Tropospheric aerosols. In: Hobbs, P. V. (Ed.), Aerosol-Cloud-Climate Interactions, Academic Press, 1-31.

Junge, C. E., 1963: Air Chemistry and Radioactivity, Academic Press, New York.

King, M. D., 1982: Sensitivity of constrained linear inversion to the selection of Lagrange multiplier. J. Atmos. Sci., 39, 1356-1369, doi: 10.1175/1520-0469(1982)039<1356: SOCLIT>2.0.CO;2. [Link]

Lovett, R. F., 1978: Quantitative measurements of airborne sea-salt in the north Atlantic. Tellus, 30, 358-364.

Lubin, D., S. K. Satheesh, G. McFarquar, and A. J. Heymsfield, 2002: Longwave radiative forcing of Indian Ocean tropospheric aerosol. J. Geophys. Res., 107, 8004, doi: 10.1029/ 2001JD001183. [Link]

Moorthy, K. K., S. K. Satheesh, and B. V. Krishna Murthy, 
1997: Investigation of the marine aerosols over tropical Indian Ocean. J. Geophys. Res., 102, 18827-18842, doi: 10.1029/97JD01121. [Link]

Moorthy, K. K., S. K. Satheesh, B. V. Krishna Murthy, 1998: Characteristics of spectral optical depths and size distributions of aerosols over tropical oceanic regions. J. Atmos. Solar. Terr. Physics, 60, 981-992, doi: 10.1016/S13646826(98)00044-3. [Link]

Moorthy, K. K., K. Niranjan, B. Narasimhamurthy, V. V. Agashe, and B. V. K. Murthy, 1999: Aerosol Climatology over India: ISRO GBP MWR Network and Database, Scientific Report, ISRO GBP SR-03-99, Indian Space Research Organization, Bangalore, Inida.

Moorthy, K. K., A. Saha, B. S. N. Prasad, K. Niranjan, D. Jhurry, and P. S. Pillai, 2001: Aerosol optical depths over peninsular India and adjoining oceans during the INDOEX campaigns: Spatial, temporal and spectral characteristics. J. Geophys. Res., 106, 28539-28554, doi: 10.1029/2001 JD900169. [Link]

Moorthy, K. K., S. Suresh Babu, and S. K. Satheesh, 2003: Aerosol spectral optical depths over the Bay of Bengal: Role of transport. Geophys. Res. Lett., 30, 1249, doi: 10.1029/2002GL016520. [Link]

O'Dowd, C. D. and M. H. Smith, 1993: Physicochemical properties of aerosols over the northeast Atlantic: Evidence for wind-speed-related submicron sea-salt aerosol production. J. Geophys. Res., 98, 1137-1149, doi: 10.1029/92JD 02302. [Link]

Pilinis, C., S. N. Pandis, and J. H. Seinfeld, 1995: Sensitivity of direct climate forcing by atmospheric aerosols to aerosol size and composition. J. Geophys. Res., 100, 18739-18754, doi: 10.1029/95JD02119. [Link]

Pruppacher, H. R., and J. D. Klett, 1978: Microphysics of clouds and precipitation - Atmospheric Sciences Library, Kluwer Academic Publishers.

Raes, F., 1995: Entrainment of free-tropospheric aerosol as a regulating mechanism for cloud condensation nuclei in the remote marine boundary layer. J. Geophys. Res., 100, 2893-2903, doi: 10.1029/94JD02832. [Link]

Ramanathan, V., P. J. Crutzen, J. Lelieveld, A. P. Mitra, D. Althausen, J. Anderson, M. O. Andreae, W. Cantrell, G. R. Cass, C. E. Chung, A. D. Clarke, J. A. Coakley, W. D. Collins, W. C. Conant, F. Dulac, J. Heintzenberg, A. J. Heymsfield, B. Holben, S. Howell, J. Hudson, A. Jayaraman, J. T. Kiehl, T. N. Krishnamurti, D. Lubin, G. McFarquhar, T. Novakov, J. A. Ogren, I. A. Podgorny, K. Prather, K. Priestley, J. M. Prospero, P. K. Quinn, K. Rajeev, P. Rasch, S. Rupert, R. Sadourny, S. K. Satheesh, G. E. Shaw, P. Sheridan, and F. P. J. Valero, 2001: Indian ocean experiment: An integrated analysis of the climate forcing and effects of the great Indo-Asian haze. J. Geophys. Res., 106, 28371-28398, doi: 10.1029/2001JD900133. [Link]

Sagar, R., B. Kumar, U. C. Dumca, K. K. Moorthy, and P. Pant, 2004: Characteristics of aerosol optical depths over Ma- nora Peak: A high altitude station in the central Himalaya. J. Geophys. Res., 109, D06207, doi: 10.1029/2003JD 003954. [Link]

Saha, A., K. K. Moorthy, and K. Niranjan, 2005: Interannual variations of aerosol optical depth over coastal India: Relation to synoptic meteorology. J. Appl. Met, 44, 1066-1077, doi: 10.1175/JAM2256.1. [Link]

Satheesh, S. K. and K. K. Moorthy, 1997: Aerosol characteristics over coastal regions of the Arabian Sea. Tellus, 49, 417-428, doi: 10.1034/j.1600-0889.49.issue4.7.x. [Link]

Schuster, G. L., O. Dubovik, and B. N. Holben, 2006: Angstrom exponent and bimodal aerosol size distributions. J. Geophys. Res., 111, D07207, doi: 10.1029/2005JD006328. [Link]

Schwartz, S. E., F. Arnold, J. P. Blanchet, P. A. Durkee, D. J. Hoffmann, W. A. Hoppel, M. D. King, A. A. Lacis, T. Nakajima, J. A. Ogren, O. B. Toon, M. Wndisch, 1995: Group Report: Connections between aerosol properties and forcing of climate. In: Charlson, R. J. and J. Heintzenberg (Eds.), Aerosol Forcing of Climate, John Wiley and Sons, 251-280.

Shaw, G. E., J. A. Regan, and B. M. Herman, 1973: Investigations of atmospheric extinction using direct solar radiation measurements made with a multiple wavelength radiometer. J. Appl. Meteorol., 12, 374-380, doi: 10.1175/ 1520-0450(1973)012<0374:IOAEUD>2.0.CO;2. [Link]

Shettle, E. P. and R. W. Fenn, 1979: Models for the aerosols of the lower atmosphere and the effects of humidity variations on their optical properties. Environmental research paper No.676, Air Force Geophysical Laboratory, MA, USA, AFGL-TR-79-0214.

Smirnov, A., A. Royer, N. T. O’Neill, and A. Tarussov, 1994: A study of the link between synoptic air mass type and atmospheric optical parameters. J. Geophys. Res., 99, $20967-$ 20982, doi: 10.1029/94JD01719. [Link]

Smirnov, A., B. N. Holben, T. F. Eck, I. Slutsker, B. Chatent, and R. T. Pinker, 2002: Diurnal variability of aerosol optical depth observed at AERONET (Aerosol Robotic Network) sites. Geophys. Res. Lett., 29, 2115-2118, doi: 10.1029/2002GL016305. [Link]

Tomasi, C., E. Caroli, and V. Vitale, 1983: Study of the relationship between Ångström's wavelength exponent and junge particle size distribution exponent. J. Appl. Meteorol., 22, 1707-1716, doi: 10.1175/1520-0450(1983)022 $<1707$ :SOTRBW $>2.0 . C O ; 2$. [Link]

Tripathi, S. N., S. Dey, A. Chandel, S. Srivastava, R. P. Singh, and B. N. Holben, 2005: Comparison of MODIS and AERONET derived aerosol optical depth over the Ganga Basin, India. Annales Geophysacae, 23, 1093-1101.

Vävekä, M., K. Hämeri, T. Puhakha, E. D. Nilson, H. Hohti, and J. M. Mäkelä, 2000: Effects of meteorological processes on aerosol particle size distribution in an urban background area. J. Geophys. Res., 105, 9807-9821, doi: 10.1029/1999JD901143. [Link]

Vinoj, V., S. S. Babu, S. K. Satheesh, K. K. Moorthy, and Y. J. 
Kaufman, 2004: Radiative forcing by aerosols over the Bay of Bengal region derived from shipborne, islandbased and satellite (Moderate-Resolution Imaging Spectroradiometer) observations. J. Geophys. Res., 109, D05203, doi: 10.1029/2003JD004329. [Link]

\section{APPENDIX}

$n_{\mathrm{c}}(r) \quad$ columnar size distribution of aerosols

$\tau_{\mathrm{p} \lambda} \quad$ columnar aerosol optical depth

$\alpha \quad$ Ångström wavelength exponent

$\beta \quad$ Ångström turbidity parameter

$r \quad$ radius of aerosol particles

$Q_{\text {ext }} \quad$ aerosol extinction efficiency factor $m \quad$ complex refractive index of aerosols

$\lambda \quad$ wavelength

$r_{\mathrm{mi}} \quad$ mode radius for the $i^{\text {th }}$ mode in lognormal of size distribution

$\sigma_{\mathrm{mi}} \quad$ standard deviation for the $i^{\text {th }}$ mode in lognormal size distribution

$K \quad$ normalization constant

$v \quad$ Junge power law index

$N_{\mathrm{t}} \quad$ integrated content of aerosols

$R_{\text {eff }} \quad$ effective radii

$N_{\mathrm{a}} \quad$ concentration of fine mode aerosols

$N_{\text {c }} \quad$ concentration of coarse mode aerosols 